\title{
Towards an Ontology for Software Metrics and Indicators as the Foundation for a Cataloging Web System
}

\author{
$\mathrm{M}^{\mathrm{a}}$ de los Angeles Martín, and Luis Olsina \\ GIDIS, Department of Informatics, \\ Engineering School at Universidad Nacional de La Pampa, \\ Calle 9 y 110, (6360) General Pico, La Pampa. Argentina. \\ olsinal,martinma@ing.unlpam.edu.ar
}

\begin{abstract}
So that the software and web measurement field can become a more robust engineering discipline, it is mandatory to start reaching a common agreement between researchers and other stakeholders about primitive concepts such as attribute, metric, measure, measurement and calculation method, scale, elementary and global indicator, calculable concept, among others. There are various useful recently-issued ISO standards related to software quality models, measurement and evaluation processes, however, we observe sometimes a lack of a sound consensus among the same terms in different documents or sometimes absent terms. In this work we present an ontology for software metrics and indicators -based as much as possible on the concepts of those standards, which can be useful to support different assurance processes, methods and tools in addition to being the foundation for our cataloging web system [12]. Without sound and consensuated definitions it is difficult to assure metadata consistency and, ultimately, data values are comparable on the same basis.
\end{abstract}

\section{Introduction}

Because of increasing size, complexity, and quality requirements, several problems have frequently been reported [2], such as unknown or bad product quality. The quality of web applications has often been assessed in an ad-hoc way and has primarily been based on the common sense, intuition and expertise of developers.

A common building block shared by many assessment and prediction methods that give support to assurance processes is the specification of nonfunctional requirements stemming from a sound definition and documentation of attributes and calculable concepts (e.g., quality, accessibility, productivity) and their metrics and indicators that quantify and evaluate them. In fact, huge volumes of information about attributes, metrics and indicators for different purposes and domains have been published in diverse fora and media. However, observing the rapid and caothic growth and heterogeneity of information sources related to metrics and indicators in addition to some lack of consensus in the terminology, it urges to provide mechanisms for agreeing, structuring, and retrieving that information in order to be useful to diverse software and Web assurance activities, methods, and tools.

For that end, we are building a cataloging web system that will basically provide different stakeholders with consultation, retrieval and reuse mechanisms starting from a sound specification of the diverse metadata of software metrics and indicators. One key factor for the success of a such cataloging web system is the conceptualisation of the software metrics and indicators domain formalized by an ontology. Software measurement and even more Web measurement -as a younger discipline, are currently in the stage where terminology and principles are still being defined and agreed on, nevertheless, the central role that software measurement and evaluation plays in the software and web engineering disciplines is actually out of discussion.

In order to reach that objective we started to construct a common conceptualisation for the software metrics and indicators domain, where concepts, attributes and their relationships are explicitly specified. Hence, such explicit specification of a conceptualisation is one of the core steps for building an ontology.

The sources for the proposed metrics and indicators ontology come from our own experience backed up by previous works in metrics and evaluation processes and methods, from current meetings among different interested Ibero American research groups in the area that are taking place in order to reach a consensus for a software measurement ontology, and from different softwarerelated ISO standards and recognized research articles. Taking into account some of his own previous works, Olsina $[9,11]$ authored the Web Quality Evaluation Method (WebQEM), which is grounded on the design, selection and implementation of metrics, elementary 
indicators, global indicators and their associated decision criteria, starting from a calculable concept (e.g. quality) and its model. A further research was aimed to specify Web metrics [10], and to develop a conceptual model just for metrics and its cataloging system [12]. On the other hand, other recent proposals such as the software measurement ontology documented by Genero et al. [4] inspired mainly in the terms of the ISO 15939 standard [7], has been a consultation source for our proposal -in addition, as said before, we are currently maintaining discussions with this and other research groups, where a final jointly-agreed report will be drawn. Finally, our ontology for software metrics and indicators has also been inspired on sources as ISO standards and other recognized research articles and books, mainly:

- The terminology provided in the ISO/IEC 15939 standard [7], which deals with the software measurement process.

- The terminology provided in the ISO/IEC 9126-1 standard [6], which refers mainly to the terms defined in the ISO/IEC 14598-1 standard [5].

- The Zuse book [15], which deals with a validation framework of software measurement.

- The Kitchenham et al. [8] conceptual data model for modeling collections of software data sets.

- The Brian et al [1] proposal for goal-driven definition of measures.

Undoubtedly, there are various useful articles and recently-issued ISO standards related to software quality models, measurement and evaluation processes, however, we observe very often a lack of a sound consensus among the same terms in different documents or sometimes absent terms, as we discuss later on.

Our ontology contributes to the integration of the metrics and indicators related concepts that can be useful as a subontology to a measurement/evaluation process ontology in addition to be the foundation for a metrics and indicators cataloging web system. The ontology representation language we used for the conceptualisation step is a mixture of tables as suggested in the Methontology strategy [3], and the well-known UML language, which was already used for this end $[4,10,14]$.

The rest of this article proceeds as follows. In Section 2 , we represent a semiformal ontology for metrics and indicators using the Methontology strategy and UML for explicit specification of the conceptualisation; in addition, an example is illustrated for ease the understanding of concepts. In Section 3, we outline the cataloging web system architecture as a practical application, and we explain why the ontology is a key piece in this system. A discussion about related works in the area are highlighted in Section 4. Finally, concluding remarks are drawn.

\section{An Ontology for Software Metrics and Indicators}

\subsection{The Used Strategy for the Conceptualisation Step}

A bunch of methodologies to build ontologies has been published where different principles, design criteria, and stages for ontology development were reported. However, mainly due to the fact that Ontological Engineering is still a relatively young discipline, each work group often employs its own methodology and formalism. So far we observe a lack of general consensus and standardisation about formalisms.

One of the well-known methods is the Methontology strategy, which provides guidelines for specifying ontologies at the knowledge level, particularly, how to deal with the specification for conceptualisation. It proposes an effective, generally applicable method for domain knowledge model construction and validation as well. This methodology was developed by Fernandez et al [3] and includes a set of stages and strategies: identification of the ontology development process where the main activities are represented (planning, evaluation, configuration management, integration, documentation, implementation, etc.); a life cycle based on evolving prototypes; and the methodology itself, which specifies at least the following steps:

Step 1: Specification. The ontology specification's goal is to put together a document that covers the ontology primary objective, purpose, granularity level and scope. The aim is to identify the terms to be represented, their characteristics, and their granularity.

Step 2: Conceptualisation. When most of the knowledge has been adquired, the ontologist has a lot of unstructured knowledge that must be organized. Conceptualisation helps to organize and structure the adquired knowledge using an external representation language that is independent of implementation languages and environments. Specifically, an informally perceived view of a domain into a semiformal specification is organized and structured using a set of intermediate representations that the domain expert and ontologist can understand.

Step 3: Implementation. It consists in implementing the conceptual model into a formal language like Ontolingua, RDF/S (Resource Description Framework/Schema) [16], or OWL (Ontology Web Language) - that also is a $\mathrm{W} 3 \mathrm{C}$ initiative, etc.

Step 4: Evaluation. Evaluation means to carry out a technical judgment of the ontology, its software environment and the documentation with respect to a frame of reference (e.g. the requirements specification document). 




Figure 1. A UML diagram to the ontology for software (and web) metrics and indicators 
For the metrics and indicators ontology we have employed for the conceptualisation step a mixture of tables as suggested by the Methontology strategy and the well-known UML language, which was previously used for this end [14].

As results of this step, the metrics and indicators knowledge using a UML conceptual model was yielded, where the main domain concepts and relationships are specified as classes and relationships respectively. Figure 1 shows the UML class diagram to the ontology for software metrics and indicators. In addition, an exhaustive glossary of terms, attributes and relationships are shown in tables 1, 2 and 3 respectively, where the terminology for the metrics and indicators ontology is explicitaly described. We use an adaptation of tables proposed by Methontology, mainly for space reasons (e.g. for table 1, we could have added synonymous terms).

In the next subsection we will describe some aspects of the conceptualisation step for the metrics and indicators ontology in a practical way.

Table 1. Software metrics and indicators ontology: Glossary of Concepts.

\begin{tabular}{|c|c|}
\hline Concept Name & Description \\
\hline Attribute & A measurable physical or abstract property of an entity [5]. \\
\hline $\begin{array}{l}\text { Calculable } \\
\text { Concept }\end{array}$ & Abstract relationship between attributes of entities and information needs [7]. \\
\hline Calculation & Activity that uses an indicator definition in order to produce an indicator's value. \\
\hline $\begin{array}{l}\text { Calculation } \\
\text { Method }\end{array}$ & $\begin{array}{l}\text { The particular logical sequence of operations specified for allowing the realisation of a formula or } \\
\text { indicator description by a calculation. }\end{array}$ \\
\hline $\begin{array}{l}\text { Categorical } \\
\text { Scale }\end{array}$ & $\begin{array}{l}\text { A scale where the measured or calculated values are categories, and can not be expressed in units, } \\
\text { in a strict sense. }\end{array}$ \\
\hline Concept Model & $\begin{array}{l}\text { The set of sub-concepts and the relationships between them, which provide the basis for } \\
\text { specifying the concept requirement and its further evaluation or estimation. }\end{array}$ \\
\hline \begin{tabular}{l|} 
Decision \\
Criteria \\
\end{tabular} & $\begin{array}{l}\text { Thresholds, targets, or patterns used to determine the need for action or further investigation, or to } \\
\text { describe the level of confidence in a given result [7]. }\end{array}$ \\
\hline Direct Metric & A metric of an attribute that does not depend upon a metric of any other attribute. \\
\hline \begin{tabular}{|l|} 
Elementary \\
Indicator
\end{tabular} & $\begin{array}{l}\text { An indicator that does not depend upon other indicators to evaluate or estimate a calculable } \\
\text { concept. }\end{array}$ \\
\hline $\begin{array}{l}\text { Elementary } \\
\text { Model }\end{array}$ & Algorithm or function with associated decision criteria that model an elementary indicator. \\
\hline Entity & Object that is to be characterised by measuring its attributes [7]. \\
\hline Function & $n$ or formula performed to combine two or more metrics. \\
\hline \begin{tabular}{|l|} 
Global \\
Indicator \\
\end{tabular} & An indicator that is derived from other indicators to evaluate or estimate a calculable concept. \\
\hline $\begin{array}{l}\text { Global } \\
\text { Model }\end{array}$ & Algorithm or function with associated decision criteria that model a global indicator. \\
\hline Indicator & $\begin{array}{l}\text { The defined calculation method and scale in addition to the model and decision criteria in order to } \\
\text { provide an estimate or evaluation of a calculable concept with respect to defined information } \\
\text { needs. }\end{array}$ \\
\hline Indicator Value & The number or category assigned to a calculable concept by making a calculation. \\
\hline Indirect Metric & A metric of an attribute that is derived from metrics of one $o$ \\
\hline $\begin{array}{l}\text { Information } \\
\text { Need }\end{array}$ & Insight necessary to manage objectives, goals, risks, and problems [7]. \\
\hline Measure & The number or category assigned to an attribute of an entity by making a measurement [5]. \\
\hline Measurement & Activity that uses a metric definition in order to produce a measure's value. \\
\hline \begin{tabular}{|l|} 
Measurement \\
Method
\end{tabular} & $\begin{array}{l}\text { The particular logical sequence of operations and possible heuristics specified for allowing the } \\
\text { realisation of a metric description by a measurement. }\end{array}$ \\
\hline Method & $\begin{array}{l}\text { Logical sequence of operations and possible heuristics, specified generically, for allowing the } \\
\text { realisation of an activity description. }\end{array}$ \\
\hline Metric & The defined measurement or calculation method and the measurement scale. \\
\hline Numerical Scale & $\begin{array}{l}\text { A scale where the measured or calculated values are numbers that can be expressed in units, in a } \\
\text { strict sense. }\end{array}$ \\
\hline
\end{tabular}




\begin{tabular}{|l|l|}
\hline Concept Name & Description \\
\hline Scale & A set of values with defined properties [5]. \\
\hline Software Tool & It is a tool that automates partially or totally a measurement or calculation method. \\
\hline Unit & $\begin{array}{l}\text { Particular quantity, defined and adopted by convention, with which other quantities of the same } \\
\text { kind are compared in order to express their magnitude relative to that quantity [7]. }\end{array}$ \\
\hline
\end{tabular}

Table 2. Software metrics and indicators ontology: Attributes Description.

\begin{tabular}{|c|c|c|}
\hline Concept & Attribute & Description \\
\hline \multirow{4}{*}{ Attribute } & name & Name of an attribute to be identified. \\
\hline & definition & An unambiguous description of the attribute meaning \\
\hline & objective & Goal or purpose to measuring this attribute \\
\hline & type & Attributes can be internal or external [6]. \\
\hline \multirow{2}{*}{$\begin{array}{l}\text { Calculable } \\
\text { Concept }\end{array}$} & name & Name of a calculable concept to be identified. \\
\hline & description & An unambiguous description of the calculable concept meaning. \\
\hline Calculation & timePoint & Instant when a calculation is performed. \\
\hline $\begin{array}{l}\text { Categorical } \\
\text { Scale }\end{array}$ & allowedValues & List of literals indicating the valid values of a categorical scale. \\
\hline \multirow{3}{*}{$\begin{array}{l}\text { Concept } \\
\text { Model }\end{array}$} & name & Name of a concept model to be identified. \\
\hline & specification & A formal or semiformal representation of a concept model. \\
\hline & references & $\begin{array}{l}\text { References to bibliographical or URL resources, where additional and } \\
\text { authoritative information of a given concept model can be consulted. }\end{array}$ \\
\hline \multirow{3}{*}{$\begin{array}{l}\text { Decision } \\
\text { Criteria }\end{array}$} & name & Name of a decision criterion to be identified. \\
\hline & description & An unambiguous description of the decision criterion meaning. \\
\hline & range & $\begin{array}{l}\text { Numerical values specifying e.g. the lower/upper thresholds for a given } \\
\text { criterion. }\end{array}$ \\
\hline \multirow{2}{*}{$\begin{array}{l}\text { Elementary } \\
\text { Model }\end{array}$} & name & Name of an elementary model to be identified. \\
\hline & specification & $\begin{array}{l}\text { A formal or semiformal representation of an elementary model. It can be e.g. a } \\
\text { mathematical or logical representation }\end{array}$ \\
\hline \multirow{2}{*}{ Entity } & name & Name of an entity to be identified. \\
\hline & description & An unambiguous description of the entity meaning \\
\hline Function & specification & A formal or semiformal representation of a function. Synonymous: formula. \\
\hline \multirow{2}{*}{$\begin{array}{l}\text { Global } \\
\text { Model }\end{array}$} & name & Name of a global model to be identified. \\
\hline & specification & $\begin{array}{l}\text { A formal or semiformal representation of a global model. It can be e.g. a } \\
\text { mathematical or logical representation }\end{array}$ \\
\hline \multirow{4}{*}{ Indicator } & name & Name of an indicator to be identified. \\
\hline & accuracy & $\begin{array}{l}\text { A quantification of the accuracy level inherent to the way of producing the } \\
\text { value of an indicator. }\end{array}$ \\
\hline & references & $\begin{array}{l}\text { References to bibliographical or URL resources, where additional and } \\
\text { authoritative information of the given indicator can be consulted. }\end{array}$ \\
\hline & valueType & Type of value that an indicator can assume. It can be a symbol, integer or float. \\
\hline $\begin{array}{l}\text { Indicator } \\
\text { Value }\end{array}$ & value & Numerical or categorical result assigned to an indicator [7]. Synonymous: data. \\
\hline $\begin{array}{l}\text { Information } \\
\text { Need }\end{array}$ & description & An unambiguous textual statement describing the information needs \\
\hline Measure & value & Numerical or categorical result assigned to an attribute. Synonymous: data. \\
\hline Measurement & timePoint & Instant when a measurement is performed. \\
\hline $\begin{array}{l}\text { Measurement } \\
\text { Method }\end{array}$ & type & $\begin{array}{l}\text { Indicates the type of measurement method that depends on the nature of the } \\
\text { operations used to quantify an attribute. Two types may be distinguished: } \\
\text { subjective (quantification involving human judgement), and objective } \\
\text { (quantification based on numerical rules) [7]. }\end{array}$ \\
\hline \multirow{2}{*}{ Method } & name & Name of a method to be identified. \\
\hline & specification & A formal or semiformal description of a method. \\
\hline
\end{tabular}




\begin{tabular}{|l|l|l|}
\hline Concept & Attribute & Description \\
\hline \multirow{5}{*}{ Metric } & name & Name of a metric to be identified. \\
\cline { 2 - 3 } & valueInterpretation & $\begin{array}{l}\text { An unambiguous textual statement for helping stakeholders to understand the } \\
\text { obtained value meaning, e.g. the closer to zero the better. }\end{array}$ \\
\cline { 2 - 3 } & objective & Goal or purpose for applying the specific metric \\
\cline { 2 - 3 } & references & $\begin{array}{l}\text { References to bibliographical or URL resources, where additional and } \\
\text { authoritative information of the given metric can be consulted. }\end{array}$ \\
\cline { 2 - 3 } $\begin{array}{l}\text { Numerical } \\
\text { Scale }\end{array}$ & valueType & Type of value that a metric can assume. It can be a symbol, integer or float. \\
\cline { 2 - 3 } Scale & type & $\begin{array}{l}\text { A quantifier of the accuracy level inherent to the way of producing the value of } \\
\text { a metric. }\end{array}$ \\
\hline \multirow{4}{*}{ Software Tool } & A numerical scale can be continuous or discrete. \\
\cline { 2 - 3 } & scaleType & $\begin{array}{l}\text { The type of scales depends on the nature of the relationship between values of } \\
\text { the scale [7]. These types of scales are commonly defined: nominal, ordinal } \\
\text { (restricted or unrestricted), interval, ratio, and absolute. }\end{array}$ \\
\cline { 2 - 3 } & version & Name of a software tool to be identified. \\
\cline { 2 - 3 } & provider & An unambiguous description of a software tool. \\
\hline \multirow{2}{*}{ Unit } & name & Indicates the name (or URL) of a software tool supplier. \\
\cline { 2 - 3 } & description & Name of a unit to be identified. \\
\hline
\end{tabular}

Table 3. Software metrics and indicators ontology: Relationships Description.

\begin{tabular}{|c|c|}
\hline Name & Description \\
\hline associated_with & One or more measurable attributes are associated with one or more entities. \\
\hline automated_by & One or more methods can be automated by none or several software tools. \\
\hline combines & A calculable concept combines (associates) one or more measurable attributes. \\
\hline contains & A metric or an indicator contain a specific scale. \\
\hline describes & $\begin{array}{l}\text { One or more calculable concepts are defined in order to satisfy a concrete information need. So, } \\
\text { a calculable concept describes a concrete information need. }\end{array}$ \\
\hline $\begin{array}{l}\text { evaluates/ } \\
\text { estimates }\end{array}$ & An indicator evaluates/estimates a calculable concept. \\
\hline expressed_in & $\begin{array}{l}\text { A numerical scale must be expressed in a specific unit. (In a strict sense, there is no idea of unit } \\
\text { for categorical scales) }\end{array}$ \\
\hline has & An indicator model has one or more decision criteria. \\
\hline includes & $\begin{array}{l}\text { A metric includes a specific measurement and/or calculation method. An indicator includes a } \\
\text { specific calculation method. }\end{array}$ \\
\hline interprets & An elementary indicator may interpret none or one specific metric. \\
\hline modeled_by & An elementary (or global) indicator is modeled by one elementary (or global) model. \\
\hline produces & A measurement (or calculation) activity produces a specific measure (or indicator) value. \\
\hline quantifies & One or more metrics can quantify an attribute. \\
\hline refers-to & $\begin{array}{l}\text { A measurement activity is related to a metric (description). None or several measurements can } \\
\text { be made on the same metric. }\end{array}$ \\
\hline related_indicators & A global indicator can be structured (aggregated) on the basis of two or more related indicators. \\
\hline related_metrics & An indirect metric can be structured on the basis of two or more related metrics. \\
\hline related-to & $\begin{array}{l}\text { A calculation activity is related to an indicator (description). None or several calculations can be } \\
\text { made on the same indicator. }\end{array}$ \\
\hline represented_by & A calculable concept can be represented by none or several concept models. \\
\hline specified_by & An indirect metric is specified by a given function (or formula). \\
\hline sub & $\begin{array}{l}\text { A calculable concept may be composed of none or several sub-concepts, which are in turn } \\
\text { calculable concepts. }\end{array}$ \\
\hline subEntity & An entity may be composed of none or several sub-entities, which are in turn entities. \\
\hline
\end{tabular}




\subsection{A Practical Description}

In order to illustrate the main concepts, attributes and relationships, we will develop an example of calculable concepts, attributes, metrics and indicators, among others.

The selection and/or definition of appropiate attributes and indicators to address an information need starts with the specification of a calculable concept to be evaluated or estimated. A calculable concept is an abstract relationship between attributes of entities an information needs. For example, a simple information need may be "evaluate the link reliability for static pages of a website". The calculable concept in this case is link reliability. Additional examples of calculable concepts includes quality, accessibility, productivity, etc.

Considering the level of abstraction a calculable concept can be composed of other subconcepts, which could be represented by a concept model (e.g. ISO 91261 specifies a quality model based on characteristics and subcharacteristics). A calculable concept is associated to one or more attributes of entities.

An entity is an object, tangible or intangible, that is characterised by measuring its attributes. Types of entities of interest to SE and WE are: Project, Product, Service, Process, and Resource. To our example, the web pages are the (product) entity.

The attribute is a measurable property of an entity. An entity may have many attributes; only some of them may be of interest for a calculable concept. For instance, in Fig. 2 we present attributes that are part of the link reliability calculable concept, and a simple concept model is shown (this is an exerpt of the quality model specified in [11]).

\section{Link Reliability}

1.1 Internal Broken Links (IBL)

1.2 External Broken Links (EBL)

1.3 Invalid Links (IL)

\section{Figure 2. A concept model for the Link Reliability calculable concept}

For a given attribute, there is always at least an empirical relationship of interest that can be captured and represented in the formal domain by means of a metric, enabling us to explore the relationship mathematically. The metric contains the information of the defined measurement (and/or calculation) method an scale.

An attribute may be measured using different measurement methods and/or scales, thus one or more metrics can quantify the same attribute. (The reader can see the method definition and derived concepts in table 1 , likewise the scale and unit concepts, and the scaleType attribute definition in table 2).
For the given example, we can have the following direct metrics (see [10] for a definition of these metrics):

a) Internal Broken Links Count - \#IBL for short,

b) $\# E B L$ and

c) \#IL.

In case we need a ratio - or percentage, with regard to the total of links count (\#TL), the next indirect metrics can be defined:

d) $\% \mathrm{IBL}=(\# \mathrm{IBL} / \# \mathrm{TL}) * 100$, and so forth to e) $\%$ EBL; and f) \%IL.

For the above direct metrics the scale type is absolute, represented by a Numerical Scale with Integer value type; for the percentage metrics an absolute scale type can also be considered, as said by Zuse ([15], pp. 237-238). They are also represented by a Numerical Scale but with Real value type.

For the above a) and b) direct metrics a specific objective measurement method can be applied (e.g. a recursive algorithm that counts each 404 HTTP status code [10]), in addition a software tool can be utilized to automate the method. However for the c) direct metric, it is hard to find a tool to automate it. On the other hand, for the d), e), and f) indirect metrics, we can use a calculation method in order to perform the specified formula or function.

Finally, the unit of measurement is links for the direct metrics, or a normalized unit -as percentage, for the others.

For the indicator concept in table 1 it says: the defined calculation method and scale in addition to the model and decision criteria in order to provide an estimate or evaluation of a calculable concept with respect to defined information needs. Particularly we can have an elementary indicator that does not depend upon other indicators to evaluate or estimate a calculable concept, and a global indicator that is derived from other indicators. Besides, an elementary indicator can interpret one metric, as shown in Fig 1. We will illustrate these issues for the Link Reliability calculable concept.

An elementary indicator for each attribute of the concept model can be defined. For example, given the 1.1 attribute of Fig. 2, IBL Preference (IBL_P, for short) is the name of the elementary indicator.

The specification of the elementary model can look like this:

$$
\begin{aligned}
& \text { IBL_P }=100 \% \text { if } \% \mathrm{IBL}=0 ; \\
& \mathrm{IBL} \_\mathrm{P}=0 \% \text { if } \% \mathrm{IBL}>=\mathrm{X}_{\max } ; \\
& \text { otherwise IBL_P }=\left(\left(\mathrm{X}_{\max }-\% \mathrm{IBL}\right) / \mathrm{X}_{\max }\right) * 100 \\
& \text { if } 0<\% \mathrm{IBL}<\mathrm{X}_{\max }
\end{aligned}
$$$$
\text { where } \mathrm{X}_{\max } \text { is some agreed upper threshold such as } 3
$$

The decision criteria that a model of an indicator need to have are the agreed acceptability levels in the given 
scale; for instance, it is unsatisfactory if the range is 0 to 40 ; marginal, if it is greater than 40 and less or equal than 60 ; otherwise, satisfactory. For the other attributes of Fig. 2 , similar or different elementary indicator models and criteria can be defined.

A global indicator (GI) for evaluating the Link Reliability concept can be named as Link Reliability Preference ( $L R P)$. The specification of the global model can be to our example the linear additive scoring model as follow:

$$
\mathrm{GI}_{1}=\left(\mathrm{W}_{1.1} \mathrm{EI}_{1.1}+\mathrm{W}_{1.2} \mathrm{EI}_{1.2}+\mathrm{W}_{1.3} \mathrm{EI}_{1.3}\right)
$$

such that if the elementary indicators (EI) are in the percentage scale the following is held: that,

$0<=\mathrm{EI}_{\mathrm{i}}<=100 ;$ and the sum of weights must fulfill

$\left(\mathrm{W}_{1}+\mathrm{W}_{2}+. .+\mathrm{W}_{\mathrm{m}}\right)=1$;

if $\mathrm{W}_{\mathrm{i}}>0$; to $\mathrm{i}=1 . . \mathrm{m}(\mathrm{m}=3$, in our example $)$.

In the previous additive model, weights can model the relative importance of the attributes in a given related concept or sub-concept. On the other side, agreed decision criteria for the global model such as the acceptability levels have to be stated as well.

Indicators are ultimately the foundation for interpretation of information needs and decision-making.

\section{An Application: A Metrics and Indicators (M\&I) Cataloging Web System}

\subsection{Architectural Overview of the Cataloging Web System}

The metrics and indicators cataloging system will provide a Web-based collaborative mechanism for discussing, agreeing, and adding approved metrics and indicators to the repository on one hand, and a Web-based robust query functionality (based on semantic web principles) for consultation and reuse, on the other hand [12]. These subsystems are outlined in Fig. 3.

From the design of users' point of view, five user's role types with different responsibilities and access privileges were considered, namely: Administrators, Moderators, Reviewers, Registered Users and Tools/Agents. The user's role types were discussed in [10].

On the other side, in order to design the cataloging architecture, we have chosen a multi-level architectural style or, the so-called n-tier architecture. Basically, the system is composed of two subsystems, namely:
- $\quad$ the Metrics and Indicators Review System, and

- $\quad$ the Metrics and Indicators Semantic Query System.

The former subsystem is the responsible for the management and manipulation of the metrics and indicators for the catalog. It provides the functionality to users in order to perform the metrics reviewing process through the web and to extract data about metrics and indicators. The latter subsystem is the responsible for the publication of cataloged metrics and indicators, making use of the semantic web principles. It does not implement any management functionality; however, it must be capable of querying on-line semantic documents and repositories.

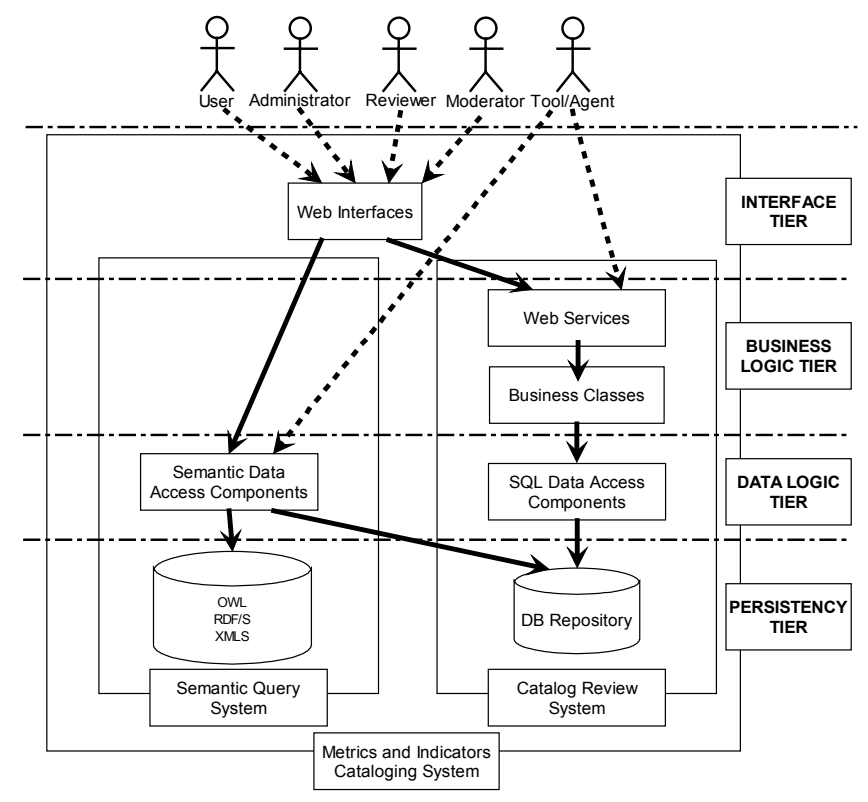

\section{Figure 3. An Architectural view of the Metrics and Indicators Cataloging Web System}

The semantic query system is made up of two core tiers:

1. Data logic tier. It contains a set of components to accede for example to different on-line repositories and documents using RQL-based semantic queries (as we show in section 3.3). It can be used by the interface layer and by other software applications (represented by Tools/Agents).

2. Persistency tier. A set of web pages and documents with semantic information about metrics and indicators (specified in OWL, RDF/RDFS and XML/XMLS). 
Table 4. RQL query examples for the metrics and indicators domain.

\begin{tabular}{|c|c|}
\hline Description & Query Example \\
\hline $\begin{array}{l}\text { 1) Retrieves all instances of attributes and } \\
\text { metrics for a sub-entity (named Webpage) }\end{array}$ & $\begin{array}{l}\text { Select X, Y, Z } \\
\text { from http://gidis.ing.unlpam.edu.ar/rdf/RDF-Metricas1\#Entity }\{X\} \text {. } \\
\text { http://gidis.ing.unlpam.edu.ar/rdf/RDF-Metricas1\#Possess }\{Y\} . \\
\text { http://gidis.ing.unlpam.edu.ar/rdf/RDF-Metricas1\#IsQuantified }\{Z\} \\
\text { Where X="Webpage" }\end{array}$ \\
\hline $\begin{array}{l}\text { 2) Retrieves all properties names and their } \\
\text { ranges to the Metric class }\end{array}$ & $\begin{array}{l}\text { Select@P, range(@P) } \\
\text { from }\{\$ \mathrm{C}\} @ \mathrm{P} \text { Where } \\
\$ \mathrm{C}=\text { ="http://gidis.ing.unlpam.edu.ar/rdf/RDF-Metricas1\#Metric" }\end{array}$ \\
\hline
\end{tabular}

\subsection{The Usefulness of the M\&I Ontology for the Cataloging Web System}

In order to contribute to the comprehension and selection process whether metrics and indicators can be useful, easy to collect and understand, a sound metrics and indicators specification, flexible documentation, consultation and retrieval mechanisms are needed. For this end, we argued that a well-designed repository of metrics and indicators and a powerful cataloging system can be efficiently used to support quality assurance processes such as nonfunctional requirement definition and specification, metrics and indicators understanding and selection, quality testing definition, amongst others. Hence, having a sound and precise metrics and indicators ontology was a key requirement for our cataloging system.

We hope this ontology proposal (that was broadened to embrace indicators concepts with regard to our previous proposal [10]), will have a good diffusion within researchers and practitioners. We are well aware this proposal can be evolved after a further discussion process among other experts in software measurement, as well as to be integrated to other related ontologies. However, the proposed metrics and indicators ontology has proven to be the foundation in the designing and prototipical implementation of the cataloging web system with semantic web power.

Particularly, one current line of research is the designing of web services in order to allow the WebQEM_Tool be able to use the repository for retrieving different metrics and indicators metadata in the design phase of an evaluation project (WebQEM_Tool is the supporting tool for the WebQEM [11] methodology).

\subsection{The Power of Semantic Queries}

In order to define queries to repositories and documents semantic web principles were used. Taking into account the semantic web technologies and languages, we are using a semantic query language as RQL ( $R D F$
Query Language) in order to retrieve the semantic information from the cataloging system.

$\mathrm{RQL}$ is a typed declarative query language, which is based on the evaluation of path expressions on RDF graphs, featuring variables on labels for both nodes (i.e., classes) and edges (i.e., properties). One of the main RQL features that distinguishes from some other RDF query languages is its capability of querying both RDF schemas and descriptions (i.e., instances).

For the M\&I Cataloging Web System this is a powerful feature for exploiting semantic documents and repositories of metrics, by allowing us not only to retrieve metrics and indicators data and its relations but also descriptive information (metadata) of available resources and services in the web, without human-processing intervention. Moreover, RQL has inference capabilities on hierarchies of classes and properties. This feature allows us exploiting additional information, even information that is not explicitly modeled in schemas.

In Table 4, we specify a pair of queries for the metrics and indicators cataloging system in order to illustrate some RQL features and powerness. In the first case, the RQL query acts only on RDF descriptions (instances) without the need of schemas. In the second case, the query retrieves all the properties information related to the Metric class, i.e. the labels of all edges.

\section{Related Works}

Unfortunately, in the last research initiatives of the SE and WE measurement and evaluation communities almost no studies have been made towards establishing a sound definition and specification of the metrics and indicators conceptual domain formalised or semiformalised by an ontology.

It is important to remark that there are various useful recently-issued ISO standards related to software quality models [6], measurement and evaluation processes [7, 5] amongst others, however, the primarily aim of these standards was to reach a consensus about the issued 
models or processes together with a consensus about the used terminology. But they do not constitute themselves a formal or semiformal ontology.

Regarding these standards we have very often observed a lack of sound consensus among the same terms in different documents or sometimes absent terms. In order to illustrate this, we will give some few examples. For instance, the "metric" term is just used in $[5,6]$ but not in [7]. Even more, [5, 6] use the terms "direct measure" and "indirect measure", meanwhile [7] uses "base measure" and "derived measure". In some cases we can state that they are synonymous terms, but in other such as metric, which is defined in [5] as "the defined measurement method and the measurement scale", there is no term with exact matching meaning in [7].

Moreover, we observe some absent terms in these standards such as "elementary indicator" and "global indicator" (even though in [7] the word "indicator" is defined with similar but not equal meaning as in our proposal), as well as the "calculation" and "calculation method" terms where are totally absent. For us, the intended objective for using a measurement method is slightly different for that of using a calculation method. The former is just intended for a measurement activity; the latter, just for a calculation activity.

The closer related work is the recent proposal of the software measurement ontology documented by Genero et al. [4], which was inspired mainly in the terms of the ISO 15939 standard. This work has been a consultation source for the present proposal, nevertheless, we have aimed mainly to the metrics and indicators ontology rather than to the measurement process ontology. Our ontology can serve as a subontology for that. In addition, we embraced specific concepts, attributes and relationships that they did not.

Finally, the REFSENO strategy [13] for specifying formally ontologies (that is rooted in Methontology) uses an ontology example for the Goal-Question-Metrics planning artifacts. Even though this example is not directly related to our ontology, the formalism has deserved our attention.

On the other hand, regarding the metrics and indicators cataloguing web system, there is almost no similar initiative in the community, as we know. Maybe the closer work is the ZD-MIS (Zuse/Drabe Measure Information System) CD-ROM delivered with the Zuse's book [15]. But we argue that our system can be more robust in delivering the information, in agreeing metrics and indicators, and in the completeness of metadata used to model metrics and indicators.

Finally, the MiniSQUID prototype [8] has also been reported as a useful tool to support metadata and data set maintenance. As we know this system was intended just for storing metrics data and metadata but not for indicators.

\section{Concluding Remarks}

In this paper we have presented and specified the main concepts and relationships of an ontology for software metrics and indicators, based as much as possible on the concepts of the quoted ISO standards, among other sources (as cited in the introduction section). This ontology can be useful to support different assurance processes, methods and tools in addition to serve as a foundation for our cataloging web system. As Kitchenham et al. said [8], without sound and consensuated definitions it is difficult to assure metadata consistency and, ultimately, data values are comparable on the same basis.

We hope this ontology proposal (that was broadened to embrace indicators concepts with regard to our previous proposal [10]), will have a good diffusion within researchers and practitioners. We are well aware this refined proposal could still be evolved after a further discussion process among other experts in the software and web measurement fields, as well as can be integrated to other related ontologies [4]. In this direction, we are helding meetings with different Ibero American related groups in order to refine and integrate our proposals. Also we are planning to held an international workshop in this specific area.

Currently, we are re-implementing the previous conceptual model of metrics with the new concepts and relationships of indicators in RDFS and OWL languages.

\section{Acknowledgments}

This research is supported partially by the UNLPam09/F022 research project. Also by the CYTED Program, in the VII.18 WEST (Web-based Software Technology) Ibero American project. We thanks the efforts made by Dr. A. Vallecillo and M. Bertoa at UM, Spain, in organizing the first joint meeting in Málaga, April, 1-2, 2003.

\section{References}

[1] Briand, L., Morasca, S. and Basili, V., "An Operational Process for Goal-driven Definition of Measures", IEEE Transactions on Software Engineering, 2002, 28(12), pp. 11061125.

[2] Deshpande, Y.; Murugesan, S., Ginige, A., Hansen, S., Schwabe, D., Gaedke, M., White, B., "Web Engineering", Journal of Web Engineering, Rinton Press, US, 2002, 1(1), pp. 61-73.

[3] Fernández López, M., Gómez-Pérez, A. and Juristo, N., "METHONTOLOGY: From Ontological Art Towards 
Ontological Engineering", Proceed. of the AAAI Symposium. University of Stanford; P.A., California, US, 1997, pp. 33-40.

[4] Genero, M.; Ruiz, F.; Piattini, M.; García, F.; and Calero, C.; "An Ontology for Software Measurement", In proceed. of SEKE'03, 15th Int'l Conference on Software Engineering and Knowledge Engineering, San Francisco, US, 2003, pp 78-84.

[5] ISO/IEC 14598-1:1999 "International Standard, Information technology - Software product evaluation - Part 1: General Overview".

[6] ISO/IEC 9126-1: 2001 "International Standard, Software Engineering - Product Quality - Part 1: Quality Model".

[7] ISO/IEC 15939: 2002 "Software Engineering - Software Measurement Process".

[8] Kitchenham B.A., Hughes R.T., Linkman S.G., "Modeling Software Measurement Data", IEEE Transactions on Software Engineering, 27(9), 2001, pp. 788-804.

[9] Olsina L., Quantitative Methodology for Evaluation and Comparison of Web Site Quality, Doctoral Thesis, (in Spanish), Ciencias Exactas School, UNLP, La Plata, Argentina, Apr. 2000. [10] Olsina, L.; Lafuente, G. Pastor, O., "Towards a Reusable Repository of Web Metrics", Journal of Web Engineering, Rinton Press, US, 1(1), 2002, pp. 61-73.

[11] Olsina L., Rossi G., "Measuring Web Application Quality with WebQEM", IEEE Multimedia, 9(4), 2002, pp. 20-29.

[12] Olsina, L.; Martin, M. A.; Fons, J.; Abrahao, S.; Pastor, O., "Towards the Design of a Metrics Cataloging System by Exploiting Conceptual and Semantic Web Approaches", In Lecture Notes in Computer Science of Springer, Int'l Conference on Web Engineering (ICWE'03), Oviedo, Spain, LNCS 2722, 2003, pp. 324-333.

[13] Tautz, C. and Von Wangenheim, C.; "REFSENO: A Representation Formalism for Software Engineering Ontologies", Fraunhofer IESE-Report No. 015.98/E, version 1.1, 1998.

[14] Wang, X. and Chan, C.W., "Ontology Modeling Using UML", 7th International Conference on Object Oriented Information Systems Conference (OOIS'2001), 2001, pp. 59-68.

[15] Zuse, H., A Framework of Software Measurement, Walter de Gruyter, Berlín-NY, 1998.

[16] W3C, WWW Consortium, 2002, "RDF Primer", W3C Working Draft 19 March 2002 http://www.w3.org/TR/2002/WDrdf-primer-20020319/ 